\title{
Parental post-traumatic reactions after premature birth: implications for sleeping and eating problems in the infant
}

\author{
B Pierrehumbert, A Nicole, C Muller-Nix, M Forcada-Guex, F Ansermet
}

Arch Dis Child Fetal Neonatal Ed 2003;88:F400-F404

See end of article for authors' affiliations

Correspondence to: Dr Pierrehumbert, Service Universitaire de Psychiatrie de l'Enfant et de

I'Adolescent, 25A Rue du

Bugnon, 1005 Lausanne,

Switzerland;

blaise.pierrehumber@@

ip.unil.ch

Accepted

23 October 2002 made it possible to increase the survival of very or Background: Progress in perinatal medicine has made it possible to increase the survival of very or
extremely low birthweight infants. Developmental outcomes of surviving preterm infants have been analysed at the paediatric, neurological, cognitive, and behavioural levels, and a series of perinatal and environmental risk factors have been identified. The threat to the child's survival and invasive medical procedures can be very traumatic for the parents. Few empirical reports have considered posttraumatic stress reactions of the parents as a possible variable affecting a child's outcome. Some studies have described sleeping and eating problems as related to prematurity; these problems are especially critical for the parents.

Objective: To examine the effects of post-traumatic reactions of the parents on sleeping and eating problems of the children.

Design: Fifty families with a premature infant (25-33 gestation weeks) and a control group of 25 families with a full term infant participated in the study. Perinatal risks were evaluated during the hospital stay. Mothers and fathers were interviewed when their children were 18 months old about the child's problems and filled in a perinatal post-traumatic stress disorder questionnaire (PPQ).

Results: The severity of the perinatal risks only partly predicts a child's problems. Independently of the perinatal risks, the intensity of the post-traumatic reactions of the parents is an important predictor of these problems.

Conclusions: These findings suggest that the parental response to premature birth mediates the risks of later adverse outcomes. Preventive intervention should be promoted.
S nce 1970, the outcomes of preterm infants (very low birth weight and extremely low birth weight) have been analysed and assessed in epidemiological, survival, ${ }^{1-3}$ and outcome studies. The last group includes follow up studies that take into account the gravity of perinatal problems and address the quality of survival according to various dimensions: (a) neurodevelopmental aspects, ${ }^{4}(b)$ cognitive development, ${ }^{56}$ (c) social competence, ${ }^{7}(d)$ socioemotional development, ${ }^{89}$ and $(d)$ behavioural problems. ${ }^{10}$

Several studies suggest that the outcomes of preterm infants are modulated by factors such as child temperament, ${ }^{11}$ parental attitudes, ${ }^{12}$ and socioeconomic variables. ${ }^{13-15}$ The long term effects of prematurity (at 4 and 8 years of age) on behaviour problems, for instance, have been found to be mediated by variables such as infant characteristics, the mother-child relationship, and family environment. ${ }^{16} 17$

The issue of parental variables is rather complex, as these variables may simultaneously be affected by premature birth and affect the premature child's outcomes. Indeed, several parental variables have primarily been considered as consequences of premature birth: (a) parental self esteem and anxiety $^{18}{ }^{19} ;(b)$ parental caregiving and interactions ${ }^{20} ;(c)$ parental representations ${ }^{21} ;(d)$ post-traumatic stress disorder (PTSD) ${ }^{22}$ It can be assumed that parental reactions to the experience of prematurity may in turn mediate the implications of premature birth.

To support the notion of such mediating effects, it would be required firstly to evidence parental reactions, and secondly to confirm their implications with respect to some of the children's outcomes, independently of the effects of the premature birth itself.
In early childhood, sleeping and eating functions are critical issues because they demonstrate the infant's ability to adjust to biological and social rhythms. Sleeping problems have been related to prematurity ${ }^{23}$; however, the relation has not proved to be completely consistent. ${ }^{24}$ Eating problems have also been related to prematurity, ${ }^{25}$ yet the relation does not seem to be universal. ${ }^{26}$ We hypothesised that sleeping and eating problems depend not only on the gravity of prematurity but also on parental reactions to the premature birth, especially posttraumatic reactions.

We therefore conducted a study with premature and full term infants. Perinatal risks were assessed during the stay in the neonatal intensive care unit for premature infants and in the maternity ward for full term infants. In a follow up at 18 months (corrected age), parents were interviewed about their children's behaviour problems, and the presence of posttraumatic reactions was retrospectively assessed.

\section{METHODS}

\section{Instruments}

The perinatal risk inventory ${ }^{27}$ is an 18 item inventory used to describe the gravity of perinatal problems and the severity of survival risks, on the basis of perinatal factors such as the Apgar index, gestational age, weight, head growth, electroencephalogram, ultrasonogram, and ventilation. Because this index is highly correlated with the duration of hospital stay and intensive care procedures, it provides a gross indication of

Abbreviations: DSM, Diagnostic and statistical manual of mental disorders; PTSD, post-traumatic stress disorders; PPQ, perinatal PTSD questionnaire 
Table 1 Characteristics of study participants

\begin{tabular}{llll}
\hline & & \multicolumn{2}{l}{ Premature subjects } \\
\cline { 3 - 4 } & Control subjects & Low risk & High risk \\
\hline Number & 25 & 23 & 27 \\
Male/female & $10 / 15$ & $13 / 10$ & $15 / 12$ \\
Socioeconomic status & $2.84(0.63)$ & $2.63(0.52)$ & $2.07(0.57)$ \\
Mothers' age (years) & $32.0(4.3)$ & $30.9(4.3)$ & $31.3(5.0)$ \\
PERI (range) & $0-2$ & $1-4$ & $5-15$ \\
Caesarean section & $5 / 25(20 \%)$ & $17 / 23(74 \%)$ & $24 / 27(89 \%)$ \\
Gestational age (weeks) & $39.9(1.1)$ & $31.3(1.5)$ & $29.3(2.0)$ \\
Birth weight (g) & $3296(485)$ & $1615(280)$ & $1131(318)$ \\
NICU (days) & $0.0(0.0)$ & $40.7(14.8)$ & $67.3(23.7)$ \\
Respiratory assistance (days) & $0.0(0.0)$ & $5.9(8.8)$ & $18.0(18.8)$ \\
Developmental quotient & $118.3(5.7)$ & $121.2(5.6)$ & $115.9(7.5)$ \\
Parity & $0.76(0.83)$ & $0.45(0.59)$ & $0.81(1.24)$ \\
Gestity & $2.28(1.37)$ & $2.26(1.35)$ & $2.70(1.93)$ \\
Infertility treatment & $0 / 25(0 \%)$ & $3 / 23(13 \%)$ & $2 / 27(7 \%)$ \\
Single mother & $0 / 25(0 \%)$ & $0 / 23(0 \%)$ & $1 / 27(4 \%)$ \\
\hline Values represent actual numbers (sex, caesarean section, infertility & treatment, single mother), ranges (PERI), or \\
means for all other variables (standard deviations in parentheses). &
\end{tabular}

the stress endured by the preterm infant. This index can also be computed for full term infants. We used a clinical cut off point (five or more points) to separate low risk and high risk newborn infants. (To determine a cut off point, we considered that, in clinical practice, premature infants without medical complications (such as mechanical ventilation for more than 24 hours after birth, infectious disease, necrotising enterocolitis, meningitis) and full term infants would have perinatal risk inventory scores of $0-4$ points.)

The perinatal PTSD questionnaire (PPQ) ${ }^{22}$ is a 14 item instrument, especially designed for parents of high risk infants, to assess the presence of traumatic memories about birth. Items relate to invasive memories ("did you have any sudden feelings as though your baby's birth was happening again?"), avoidance ("did you try to avoid thinking about childbirth or your baby's hospital stay?"), and more general post-traumatic symptoms ("did you feel more jumpy?"). Questions are retrospective; parents (mother or father) are asked to respond about symptoms that appeared since the birth, and which lasted more than one month. The posttraumatic reaction index corresponds to the sum of positive responses. The validation study conducted by the authors of this instrument showed a high correlation between the PPQ score and other well known PTSD measures such as the impact of event scale. ${ }^{28}$ We used a clinical cut off point (six or more positive responses on 14 items) to separate mild and severe post-traumatic reactions. (A clinical cut off point has been determined in the validation study of the French version of the PPQ, carried out on 158 subjects. ${ }^{29}$ With this cut off point (six or more positive responses on 14 items), the PPQ gave a sensitivity coefficient of $89 \%$ and a specificity coefficient of $87 \%$, when compared with the PTSD criteria of Hansenne et $a l^{30}$ - that is, 42 points on the impact of event scale-itself based on the Diagnostic and statistical manual of mental disorders (DSM) criteria. ${ }^{31}$ Note that Hansenne et al used DSM III-R criteria; however, they do not differ significantly from the DSM IV criteria.)

The symptom check list ${ }^{32}$ is a 30 minute semistructured interview with the mother and/or the father, aimed at exploring the parent's perception of his/her child's present health and behaviour problems. This instrument has a seven factor structure: sleeping problems, eating problems, opposition, rituals, withdrawal, aggressiveness, and skin problems. The present study focuses on sleeping and eating problems only. Five items refer to sleeping problems: trouble going to sleep (frequency); night waking (frequency and number per night); time needed to go back to sleep; evaluation of the overall consequences of these problems on the parent-child relation. Five items also refer to eating problems: quantitatively inadequate ingestion; refusal to eat (frequency); appreciation of the meal as a negative experience; vomiting (frequency); evaluation of the overall consequence of these problems on parent-child relationship. The items are coded by the interviewer on 1 to 5 point Likert scales and provide indices of sleeping and eating problems, corresponding to the total of items responded to positively. The internal consistency of these scales is satisfactory $(\alpha=0.80$ for sleeping problems and 0.73 for eating problems).

The socioeconomic status was coded according to three levels, taking into account both education and professional status (level 1 corresponds to no training and/or a position of employee, level 2 to specialised training and/or a specialised position, and level 3 to high level education and/or private practice in a profession); education and professional status were coded separately, and each parent was coded separately; scores were then averaged.

A paediatric examination includes the Griffiths developmental quotient ${ }^{33}$ and a neurodevelopmental assessment..$^{34}{ }^{35}$ The examination covers the presence of neurological abnormalities, and includes an evaluation of psychomotor problems and the visual and auditory systems.

The relations between eating or sleeping problems and socioeconomic status, sex, or later medical complications were evaluated using $r$ correlation coefficients and $t$ tests. Mean scores of children's behaviour problems and parents' posttraumatic reactions were compared (control, low risk and high risk), using analysis of variance. To test models including perinatal risks, post-traumatic reactions, and behaviour problems, we computed partial correlation coefficients.

\section{Population and procedure}

All preterm infants ( $<33$ gestation weeks) admitted to the neonatal intensive care unit of the Lausanne University Hospital over a 12 month period (January to December 1998) were considered for inclusion in the study. There were 113 surviving preterm infants (survival rate 91\%). Exclusion criteria were: infant malformation, chromosome abnormality, and fetopathy; parental psychiatric illness and/or drug abuse, and difficulty in speaking French. Twenty were excluded. Seventy three of the families contacted (78\%) agreed to participate. Three subjects were later excluded because they developed neurodevelopmental complications (cerebral palsy, deafness, serious visual impairment). Four subjects (6\%) dropped out between 0 and 18 months. Dropouts and subjects who declined to participate did not differ from participants on perinatal risk inventory scores $(t(103)=0.52, \mathrm{p}=0.59)$. 
Table 2 Perinatal risks and sleeping or eating problems

\begin{tabular}{lllllll}
\hline & & \multicolumn{2}{l}{ Premature subjects } & & \multicolumn{2}{l}{ Statistical analysis } \\
\cline { 3 - 4 } \cline { 6 - 7 } & Controls & Low risk & High risk & & $F(2,72)$ & $\mathrm{p}$ Value \\
\hline Sleeping problems & $6.56(0.70)$ & $9.30(0.85)$ & $6.92(0.81)$ & & 3.33 & 0.04 \\
Eating problems & $5.64(0.29)$ & $6.26(0.62)$ & $6.77(0.75)$ & & 0.92 & 0.40 \\
Aggregated index & $12.20(0.73)$ & $15.56(0.89)$ & $13.70(1.12)$ & 3.02 & 0.05 \\
\hline
\end{tabular}

Values are mean (SEM). Statistical analysis: analysis of variance with $F$ and $p$ values.

Table 3 Perinatal risks and post-traumatic reactions of the parents

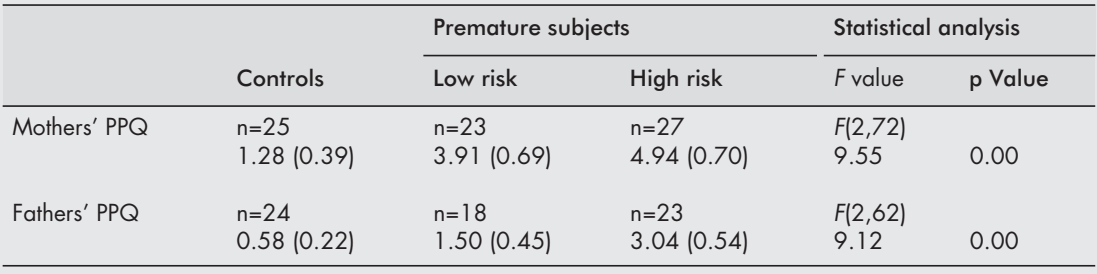

Values are mean (SEM). Statistical analysis: analysis of variance with $F$ and $p$ values.

$P P Q$, perinatal post-traumatic stress disorder questionnaire.

There were five cases of multiple birth; only one child (randomly selected) was kept for the study; seven children were then removed. Nine families had missing data (PPQ or symptom check list). Analyses could therefore be performed on 50 families with an 18 month old premature infant without neurodevelopmental complications.

Control subjects were recruited from the maternity ward of the same hospital, during the three to four day hospital stay of the mother and newborn. Exclusion criteria were: problems during pregnancy or delivery; somatic abnormalities; psychiatric problems in parents; language difficulties. The acceptance rate was $38 \%$. The drop out rate between 0 and 18 months was $11 \%$. Analyses could therefore be performed on 25 families. Table 1 gives the sample characteristics.

The follow up visit took place when the children were 18 months of corrected age (mean (SD) age 18.3 (0.6) months); mothers (when possible with fathers) responded to the symptom check list interview and filled in the PPQ. Only 65 fathers responded to the PPQ. The child's neurodevelopmental assessment as well as an anamnestic interview were conducted during that visit.

The procedures were approved by the ethics committee for clinical research at Lausanne University Medical School.

\section{RESULTS}

\section{Sleeping or eating problems in relation to} socioeconomic status and sex

In spite of socioeconomic differences between the three groups, there were no significant correlation coefficients between sleeping or eating problems and the family's socioeconomic status $(r=-0.10, \mathrm{p}=0.38 ; \quad r=-0.04$, $\mathrm{p}=0.71)$. There were no relations between sex and sleeping or eating problems $(t(73)=0.60, \mathrm{p}=0.55 ; t(73)=1.61$, $\mathrm{p}=0.11)$.

\section{Sleeping or eating problems in relation to medical complications}

Apart from one child with visual problems, the paediatric examination found no other neurodevelopmental complications at 18 months. Twelve premature and four full term children had to be readmitted to hospital for various medical complications. We compared sleeping and eating problems of children according to whether they had been readmitted or not. The $t$ tests showed no significant differences $(t(73)=0.44, \mathrm{p}=0.65 ; t(73)=0.17, \mathrm{p}=0.86)$. Therefore the presence of sleeping or eating problems can be considered as having no association with medical complications.

\section{Perinatal risks and sleeping or eating problems}

About two thirds of premature subjects were reported to have no problems (five responses rated 1) or only one slight problem (one response rated 2), on either sleeping or eating problem scales. Sleeping and eating problems proved to be independent $(r=-0.12)$. In order to increase the sensibility of the problem scales, we aggregated the two indices, specifying the presence of one or both kinds of problems. Table 2 presents sleeping and eating problems in control and premature subjects (low and high risk), considering the specific and aggregated indices. Low risk premature children had higher scores than their high risk counterparts and the control subjects with respect to sleeping problems and the aggregated index of problems.

\section{Perinatal risks and post-traumatic reactions}

We evaluated the impact of perinatal risks on post-traumatic reactions of the parents. We first compared the three groups according to the parents' PPQ index (table 3). Parents of premature children had higher indices of post-traumatic reaction. Moreover, the severity of the perinatal risk clearly increases the likelihood of the parents developing post-traumatic stress reactions. When we used the clinical cut off point ( six or more positive responses on 14 items) of the PPQ, 1/25 control mothers (4\%), 6/23 mothers of the low risk group (26\%), and $11 / 27$ mothers of the high risk group (41\%) exhibited post-traumatic reactions in the clinical range (referring to the DSM criteria).

\section{Post-traumatic reactions of the parents and sleeping or} eating problems

We next evaluated the impact of parental post-traumatic reactions (PPQ) on later problems. As shown in table 4, there were clear differences between full term children, premature children of mothers with mild post-traumatic reactions, and premature children of mothers with severe post-traumatic reactions, as far as sleeping problems and the aggregated index of problems were concerned (only the second being significant). None of the differences between control children, children of fathers with mild post-traumatic reactions, and 
Table 4 Maternal post-traumatic reactions and sleeping or eating problems

\begin{tabular}{lllllll}
\hline & & \multicolumn{2}{l}{ Premature subjects } & \multicolumn{2}{l}{ Statistical analysis } \\
\cline { 3 - 4 } & Controls $(n=25)$ & $\begin{array}{l}\text { Low PPQ } \\
(n=33)\end{array}$ & $\begin{array}{l}\text { High PPQ } \\
(n=17)\end{array}$ & & $F(2,72)$ & $p$ Value \\
\hline Sleeping problems & $6.56(0.70)$ & $7.27(0.65)$ & $9.47(1.21)$ & 2.78 & 0.06 \\
Eating problems & $5.64(0.29)$ & $6.48(0.61)$ & $6.64(0.86)$ & 0.75 & 0.47 \\
Aggregated index & $12.20(0.73)$ & $13.75(0.84)$ & $16.11(1.36)$ & 3.49 & 0.03 \\
\hline
\end{tabular}

Values are mean (SEM). Statistical analysis: analysis of variance with $F$ and $p$ values.

$P P Q$, perinatal post-traumatic stress disorder questionnaire score.

Table 5 Perinatal risks, post-traumatic reactions, and problems; partial corrrelations

\begin{tabular}{lllll}
\hline Correlation variables: & PERI & Mat.PPQ & PERI & Pat.PPQ \\
\hline Control variables: & Mat.PPQ & PERI & Pat.PPQ & PERI \\
\hline Sleeping problems & -0.05 & $0.28^{*}$ & 0.00 & 0.08 \\
Eating problems & 0.06 & 0.12 & 0.03 & $0.27^{*}$ \\
Aggregated index & 0.00 & $0.31^{* *}$ & 0.01 & $0.24^{*}$ \\
\hline
\end{tabular}

Values are partial correlation coefficients $r(72)$ between the three indices of problems and respectively: the risk index (PERI) with maternal post-traumatic reactions (Mat.PPQ) controlled (column 1); maternal post-traumatic reactions with the risk index controlled (column 2). Columns 3 and 4 provide the same coefficients for paternal post-traumatic reactions.

$P E R I$, Perinatal risk inventory; $P P Q$, perinatal post-traumatic stress disorder questionnaire score.

${ }^{*} p<0.05 ;{ }^{* *} p<0.01$

children of fathers with severe post-traumatic reactions were significant (results not shown).

\section{Severity of perinatal risks and post-traumatic reactions and sleeping or eating problems}

As both the severity of risk and maternal post-traumatic reactions-which are linked-affect sleeping or eating problems, we wondered if the severity of risk had a specific effect on later problems, or if this effect was indirect, mediated by the presence of post-traumatic reactions.

We computed four sets of partial correlation coefficients: firstly, between the risk index and the indices of problems, keeping the maternal post-traumatic reactions constant; secondly between the maternal post-traumatic reactions and the indices of problems, keeping the risk index constant. We repeated the same analysis for paternal post-traumatic reactions. The results (table 5) clearly suggest a mediating effect of maternal and paternal post-traumatic reactions on the expression of later problems.

\section{DISCUSSION}

The progress in perinatal medical science that ensures the survival of smaller and smaller newborn infants must be considered in the light of the quality of life and wellbeing of the survivors. It is essential that parents and health professionals consider the implications of prematurity for problems later in life.

The capacity of parents to adjust to a premature birth (infant not corresponding to expectations, separation, invasive treatment, etc) has been considered to be a critical aspect in many recent studies. Premature birth may cause considerable stress for parents and result in PTSD symptoms, such as invasive memories, attempts to avoid or ignore certain specific experiences, and emotional vigilance. This may have implications with regard to the transition to parenthood, namely on parents' representations and caregiving competencies.

This study shows that prematurity and the severity of perinatal risks can, not only have direct effects on later problems but also, and perhaps more importantly, indirect effects. The failure to consider both kinds of effects may account for the inconsistencies of previous studies in the field. ${ }^{23-26}$ When we considered sleeping problems (and the aggregated index of problems), we found that the relation between problems and risks was not strictly linear: low risk premature infants had more problems than high risk and control subjects. It is possible that the relatively long stay in the neonatal intensive care unit (high risk infants) contributes to the biological rhythms. However, when we considered the effects of maternal post-traumatic reactions on sleeping problems (as well as on the aggregated index), we found a relatively strong, linear relation between children's problems and maternal posttraumatic reactions.

The severity of perinatal risks has often been considered a sensitive factor with respect to a child's later wellbeing. The present data suggest that perinatal risks induce parental posttraumatic reactions, which in turn have an effect on child outcomes. There are of course many factors that may account for the development of premature children. ${ }^{11-17}$ Nevertheless, these data suggest that the absence, or resolution, of parental post-traumatic reactions may help to attenuate the risks of developing later problems.

Although we found this pattern for the aggregated index of sleeping and eating problems, sleeping problems appear to be more affected than eating problems by perinatal risks and maternal post-traumatic reactions. It is interesting to note that eating problems seem to be affected by paternal post-traumatic reactions when perinatal risks are controlled (table 5).

These results should be considered with caution, given the relatively small sample sizes and the possible self selection bias (especially with respect to the fathers and the control group). Another limitation of this study is the fact that the problems of the children are reported by the parents. Hence, an alternative explanation for these results could be that parents with amplified post-traumatic reactions tend to dramatise their infant's situation during the semistructured interview. For instance, it is possible that these parents develop a lower tolerance to their children's problems. Regardless of the actual situation, they may provide a pessimistic image of the child's outcomes. Reciprocally, it is possible that parents of premature children who report few post-traumatic reactions, yet who had been confronted with uncertainties about their infant's survival, tend to give an overly positive image of their children in an effort to forget, or deny, any harmful implications of the premature birth. Clinical examination of interview content often found parents eager to forget everything about the experience. However, in any case, parents who express traumatic memories of their child's birth, whether the problems were real or exaggerated, appear to be far more preoccupied by their child's wellbeing than other parents, especially when it comes to biological rhythms such as sleeping and eating. For parents, sleeping and eating problems are critical because they represent a warning system for their child's wellbeing. In turn, sleeping and eating problems can affect the parents' own wellbeing.

It is important to acknowledge that post-traumatic reactions can occur after a birth and that supportive care and psychological help may be needed. ${ }^{36}$ Previous studies have 
suggested that intervention programmes for parents of infants born at risk will enable them to emotionally consolidate their experience with regard to the infant's high risk status. ${ }^{37}$ We evaluated post-traumatic reactions retrospectively (at 18 months); memories of post-traumatic reactions may have been partly reconstructed, which restricts their clinical relevance. Clinical studies in this field should assess these reactions much earlier, ${ }^{39}$ making it possible to detect parents who would need intervention programmes to reduce the risk of developing post-traumatic responses to premature birth.

\section{ACKNOWLEDGEMENTS}

The study was conducted with the collaboration of Céline Bontemps, Delphine Brun, André Calame, Sophie Castaing, Sibylle Castella-Beer, François Clément, Sarah Dieckmann, Claire-Lise Fawer, Pierre Fumeaux, Sylvaine Gamba, Martine Herren, Alain Herzog, Lyne Jaunin, Adrien Moessinger, Elise Munoz, and Françoise Savary. Bernard Plancherel provided advice for statistical analyses. The manuscript was reviewed with the help of Raphaële Miljkovitch. The study was made possible with grants from the Swiss National Science Foundation (contract No 32-49712.96) and the Fondation pour la Psychiatrie de la Petite Enfance (Lausanne).

\section{Authors' affiliations}

B Pierrehumbert, A Nicole, C Muller-Nix, F Ansermet, Service Universitaire de Psychiatrie de l'Enfant et de l'Adolescent, Lausanne, Switzerland

M Forcada-Guex, Département Médico-Chirurgical de Pédiatrie, Division de Néonatologie, Centre Hospitalier Universitaire de Lausanne, Switzerland

\section{REFERENCES}

1 Wildschut HI, Nas T, Golding J. Are sociodemographic factors predictive of preterm birth? A reappraisal of the 1958 British Perinatal Mortality Survey. Br J Obstet Gynaecol 1997; 104:57-63.

2 Hack M, Fanaroff AA. Outcomes of children of extremely low birthweight and gestational age in the 1990s. Semin Neonatol 2000;5:89-106

3 Ancel PY, du Mazaubrun C, Breart G. Grossesses multiples, lieu de naissance et mortalité des grands prématurés: Premiers résultats d'EPIPAGE-Île-de-France. J Gynécol Obstét Biol Reprod 2001;30:48-54.

4 Marret S, Marpeau L. Grande prematurite, risque de handicaps neuropsychiques et neuroprotection.J Gynécol Obstét Biol Reprod 2000;29:373-84.

5 Lee H, Barratt MS. Cognitive development of preterm low birth weight children at 5 to 8 years old. I Dev Behav Pediatr 1993:14:242-9.

6 Fawer CL, Besnier S, Forcada M, et al. Influence of perinatal, developmental and environmental factors on cognitive abilities of preterm children without major impairments at 5 years. Early Hum Dev 1995;43:151-64.

7 Tessier $\mathbf{R}$, Nadeau L, Boivin $M$, et al. The social behaviour of 11 - to 12 -year-old children born as low birthweight and/or premature infants. Int J Behav Dev 1997;21:795-811.

8 Wille DE. Relation of preterm birth with quality of infant-mother attachment at one year. Infant Behavior and Development $1991 ; 14: 227-40$

9 Wintgens A, Lepine S, Lefebvre F, et al. Attachment, self-esteem, and psychomotor development in extremely premature children at preschool age. Infant Ment Health J 1998; 19:394-408

10 Hille ETM, den Ouden AL, Saigal S, et al. Behavioural problems in children who weigh $1000 \mathrm{~g}$ or less at birth in four countries. Lancet 2001;357:1641-3

11 Sajaniemi N, Hakamies-Blomqvist L, Maekelae J, et al. Cognitive development, temperament and behavior at 2 years as indicative of language development at 4 years in pre-term infants. Child Psychiatry Hum Dev 2001;31:329-46.

12 Butcher PR, Kalverboer AF, Minderaa RB, et al. Rigidity, sensitivity and quality of attachment: the role of maternal rigidity in the early socio-emotional development of premature infants. Acta Psychiatr Scand 1993;88:38.
13 Largo RH, Pfister D, Molinari L, et al. Significance of prenatal, perinatal and postnatal factors in the development of AGA preterm infants at five to seven years. Dev Med Child Neurol 1989;31:440-56.

14 Ross G, Lipper EG, Auld PAM. Educational status and school related abilities of very-low-birthweight premature children. Pediatrics 1991;88:1125-34

15 McGauhey PJ, Starfield B, Alexander C, et al. Social environment and vulnerability of low birthweight children: a social-epidemiological perspective. Pediatrics 1991:88:943-53.

16 Goldberg S, Corter C, Lojkasek M, et al. Prediction of behavior problems in four-year-olds born prematurely. Annual Progress in Child Psychiatry and Child Development 1991:92-113.

17 Brandt P, Magyary D, Hammond M, et al. Learning and behavioral-emotional problems of children born preterm at second grade. J Pediatr Psychol 1992;17:291-311.

18 Aradine CR, Ferketich S. The psychological impact of premature birth on mother and fathers. J Reprod Infant Psychol 1990:8:75-86.

19 Casteel JK. Affects and cognitions of mothers and fathers of preterm infants. Matern Child Nurs J 1990;19:211-20.

20 Minde K, Goldberg S, Perrotta M, et al. Continuities and discontinuities in the development of 64 very small premature infants to 4 years of age. Journal of Child Psychology and Psychiatry and Allied Disciplines 1989;30:391-404

21 Fava Vizziello G, Calvo V. La perdita della speranza: effetti della nascita prematura sulla rappresentazione genitoriale e sullo sviluppo dell'attaccamento. Neuropsicologia Infantile Psicopedagogia Riabilitazione 1997;23:15-35.

22 Quinnell FA, Hynan MT. Convergent and discriminant validity of the Perinatal PTSD Questionnaire (PPQ): a preliminary study. J Trauma Stress 1999;12:193-9.

23 Ju S, Lester B, Coll CG, et al. Maternal perceptions of the sleep patterns of premature infants at seven months corrected age compared to full-term infants. Infant Ment Health J 1991;12:338-46.

24 Wolke D, Meyer R, Ohrt B, et al. The incidence of sleeping problems in preterm and fullterm infants discharged from neonatal special care units: an epidemiological longitudinal study. Journal of Child Psychology and Psychiatry and Allied Disciplines 1995;36:203-23.

25 Gerner EM. Emotional interaction in a group of preterm infants at 3 and 6 months of corrected age. Infant and Child Development 1999:8: 117-28.

26 Stjernqvist $K$. The birth of an extremely low birth weight infant (ELBW) <901 g: impact on the family after 1 and 4 years. J Reprod Infant Psychol 1996;14:243-54.

27 Scheiner AP, Sexton ME. Prediction of developmental outcome using a perinatal risk inventory. Pediatrics 1991;88:1135-43.

28 Horowitz M, Wilner N, Alvarez W. Impact of event scale: a measure of subjective stress. Psychosom Med 1979;41:209-18.

29 Pierrehumbert B, Nicole A, Muller-Nix C et al. Validation française $d^{\prime} u n$ questionnaire de stress posttraumatique destiné aux parents d'enfants à haut risque périnatal. Annales Médico-Psychologiques 2003 ; in press.

30 Hansenne $\mathbf{M}$, Charles $G$, Pholien $P$, et al. Mesure subjective de l'impact d'un événement: traduction française et validation de l'échelle d'Horowitz. Psychologie Médicale 1993;25:86-8.

31 American Psychiatric Association. Diagnostic and statistical manual of mental disorders. 4th ed (DSM-IV). Washington DC: American Psychiatric Association, 1994

32 Robert-Tissot C, Rusconi-Serpa S, Bachmann JP, et al. Le questionnaire SCL (Symptom check-list). In: Lebovici S, Mazet P, Visier JP, eds. L'évaluation des interactions précoces entre le bébé et ses partenaires. Paris, Genève: Eshel et Médecine et Hygiène, 1989:179-216.

33 Griffiths R. The abilities of babies. London: University of London Press, 1970.

34 Amiel-Tison C, Grenier A. Neurological assesment during the first year of life. New York: Oxford University Press, 1986

35 Sheridan MD. Manual for the STYCAR vision test. Berkshire: NFER Publishing Company, 1969.

36 Lyons S. A prospective study of post traumatic stress symptoms 1 month following childbirth in a group of 42 first-time mothers. J Reprod Infant Psychol 1998;16:91-105.

37 Meyer EC, Zeanah CH, Boukydis CF, et al. A clinical interview for parents of high-risk infants: concept and applications. Infant Ment Health J 1993; 14:192-207.

38 Meyer EC, Coll CT, Lester BM, et al. Family-based intervention improves maternal psychological well-being and feeding interaction of preterm infants. Pediatrics 1994;93:241-6.

39 Meyer EC, Coll CT, Seifer R, et al. Psychological distress in mothers of preterm infants. J Dev Behav Pediatr 1995;16:412-17. 